\title{
Urologie
}

\section{Macht die Sitzheizung im Auto Männer unfruchtbar?}

\section{Frage von A.:}

Wie wirkt sich eine Sitzheizung im Auto bei längerem Gebrauch auf Fruchtbarkeit, Erektion, Ejakulation, Hormonproduktion usw. beim Mann aus?

Gibt es Erkenntnisse, wie lange eine Sitzheizung eingesetzt werden kann, ohne Schaden auf diesem Gebiet zu verursachen, dabei aber den Vorteil für Rücken/Bandscheiben zu nutzen?

\section{Antwort von Dr. med. W. Merkle, Wiesbaden:}

Das ist eine interessante Frage - die allerdings nach meiner Kenntnis bisher nie in Studien untersucht wurde. Dennoch gibt es ein paar Hinweise, die als Teilantwort dienen können:

- Es ist bekannt, dass Wärme die Spermienqualität negativ beeinflusst, und es gibt Daten, dass Kühlung (in Maßen!) die Spermienqualität verbessern kann. Insofern hat Wärme einen Einfluss. Ich gehe davon aus, dass Sie nicht Hunderte von Kilometern bzw. viele Stunden

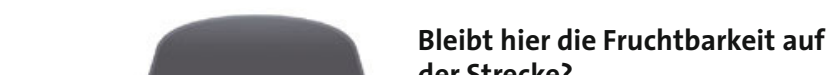
der Strecke?

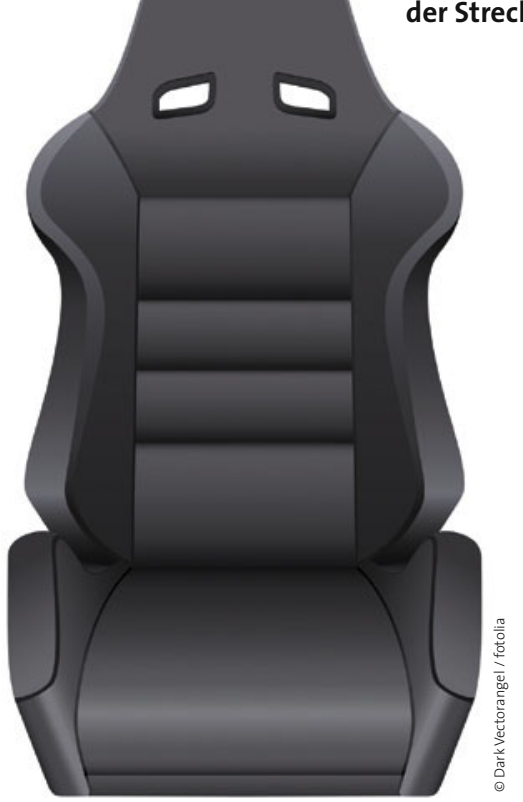

auf einem geheizten Sitz verbringen. Und kurzzeitige Wärmeanwendung ist wohl kaum geeignet, dauerhafte biolo-

\section{Traumatologie}

\section{Schmerzen nach Treppensturz - was hilft?}

\section{Frage von Dr. E. M.:}

Welche Medikamente sind zur Schmerztherapie nach einem Treppensturz mit starken bewegungsabhängigen Schmerzen am hinteren Beckenkamm und der Nierenregion zu empfehlen? Nicht müde machend. Frakturen und Nierenbeteiligung sind ausgeschlossen. Hämatome nicht sichtbar.

\section{Antwort von Dr. M. Laufer, Leipzig:}

In diesem Fall würde ich ein NSAR (z.B. Diclofenac bis $150 \mathrm{mg} / \mathrm{d}$ ) empfeh- len. Kommt man damit nicht zum Ziel, wäre evtl. der parallele Einsatz eines Opiates (z.B. retardiertes Tilidin oder Tramadol) unter Beachtung der eingeschränkten Fahrtauglichkeit zu erwägen.

\footnotetext{
- Dr. med. Mario Laufer, Klinik und Poliklinik für Anästhesiologie und Intensivtherapie am Universitätsklinikum Leipzig, Liebigstraße 20, D-04103 Leipzig
}

gische Veränderungen hervorzurufen (zumindest nicht im Temperaturbereich einer Sitzheizung).

- Die Erektion ist auch abhängig von der muskulären Spannung im Beckenboden. Insofern hat Wärme einen positiven Einfluss, solange sie wirkt. Allerdings ist der Autositz kaum der Ort, an dem Sie eine entspannende Wärmetherapie durchführen. Dafür gibt es bessere Systeme und Orte.

- Testosteron wird durch Wärme beeinflusst - das zu beachten ist in der Biochemie wichtig, wenn man Testosteron bestimmt (z.B. im Chromatografen). Klinische Daten sind mir dazu aber nicht bekannt.

- Positive Einflüsse der Vermeidung von Kälte im Beckenboden sind beim Wasserlassen und in der Therapie des Beckenbodenschmerzes bekannt. Hier wirkt die Sitzheizung im kalten Auto sicher positiv.

Für mich bedeutet dies - da die Einwirkungszeit einer Sitzheizung i.d.R. kurzfristig ist -, dass negative Effekte nicht zu erwarten sind. Diese bräuchten längere (Dauer-)Einwirkungszeiten selbst wenn der Winter (hoffentlich nicht!) lang wäre.

\footnotetext{
- Dr. med. Walter Merkle, Deutsche Klinik für Diagnostik, Aukammallee 33, D-65191 Wiesbaden
} therapie, zu einer unklaren Diagnose, einem ungewöhnlichen Krankheitsverlauf ...? Unsere Expertenräte helfen Ihnen gerne weiter. Sie erreichen sie unter http://www.springermedizin.de 